\title{
CORIMA
}

Córima, Revista de Investigación en Gestión Cultural

ISSN electrónico: 2448-7694

Universidad de Guadalajara

Sistema de Universidad Virtual

México

corima@udgvirtual.udg.mx

Año 3, número 4, enero-junio 2018

\section{Cultura, Território e Política Regional no Estado da Bahia, Brasil}

\author{
Janaina Santos Dias ${ }^{1}$ \\ Frederico Lustosa da Costa \\ Universidade Federal Fluminense, Brasil
}

DOI: $10.32870 /$ cor.a3n4.7067

[Recibido: 29/09/2017; aceptado para su publicación: 15/11/2017]

\section{Resumo}

O presente trabalho consiste em uma análise da política de desenvolvimento regional do estado da Bahia a partir da abordagem cultural do espaço - os Territórios de Identidade. A partir de novas interpretações, propõe uma reflexão sobre os paradigmas contemporâneos de desenvolvimento, na busca da construção de campos epistemológicos que focalizem a cultura e os territórios como fatores primordiais no processo de mudança social nos níveis local e regional. Empreende uma análise do modelo de desenvolvimento que o governo baiano vem tentando implementar, buscando identificar seus desafios na proposição de suas políticas públicas capazes de reconhecer e conformar a diversidade cultural dos 27 territórios que compõem o estado.

\footnotetext{
${ }^{1}$ Correo electrónico: janainadias@id.uff.br

CÓMO CITAR ESTE ARTÍCULO:

Lustosa da Costa, F., Santos Dias, J. (2018). Cultura, Território e Política Regional no Estado da Bahia, Brasil. Córima, Revista de Investigación en Gestión Cultural, 3(4). doi: 10.32870/cor.a3n4.7067
} 


\section{Palavras-chave}

Cultura e desenvolvimento regional, cultura e território, cultura e política pública.

\section{Introdução}

As relações entre cultura, território e desenvolvimento constituem tema de grande relevância na atualidade. Os últimos trinta anos têm sido pródigos em contradições, acentuando aa mundialização de diferentes processos, códigos e linguagens e, ao mesmo tempo, fortalecendo a reivindicação das identidades locais, da cultura popular e de tudo aquilo que se enraíza n o entorno físico, ou seja, o "território".

O debate sobre o desenvolvimento vem se ampliando para ir além das variáveis econômicas, que são extremamente importantes, mas não suficientes para balizar o desenvolvimento social justo e ambientalmente sustentável. Ou seja, o desenvolvimento econômico não se legitima independentemente de suas dimensões sociais e culturais. Dessa forma, os fatores de ordem social, institucional e cultural são reconhecidos como impactantes na produção de melhores formas de interação social (BARBOSA DA SILVA, 2010, p.7). Nessa perspectiva, conceitos e estratégias são ressignificados para a construção de um novo modelo de desenvolvimento que trazem a cultura como alicerce.

No entanto, a cultura, muitas vezes, continua aparecendo ainda como um ornamento supérfluo, como uma forma de lazer, de entretenimento, o que impede de percebê-la como pensamento, imaginação, criatividade, racionalidade e emoção, como o meio por onde construímos e partilhamos os sentidos de vida. A cultura hoje ainda não pouco concebida como uma dimensão da identidade individual e coletiva inserida na dinâmica do processo de desenvolvimento e que pode e deve ser integrada num projeto coletivo de transformação.

Dessa forma, cumpre destacar e valorizar as especificidades e diferenças culturais que têm levado diferentes lugares, países, cidades e governos a optarem por estratégias de desenvolvimento que resultam na afirmação, reconstrução e valorização de sua própria identidade cultural.

Nessa perspectiva, o governo do estado da Bahia, em sua política de desenvolvimento local e regional, vem afirmando que a cultura é um fator primordial de mudança social. O desenvolvimento do estado está calcado nas práticas sociais e nas representações através das quais as populações dos territórios constroem o sentido de suas existências. Assim, o goerno do estado 
tem tomado os seus 27 Territórios de Identidade ${ }^{2}$ como espaços de articulação de estratégias de desenvolvimento regional.

O objeto de análise aqui considerado é o modelo de desenvolvimento regional do estado da Bahia, apoiado na abordagem territorial com aspectos de natureza cultural e identitária. Esse modelo perpassa os temas da cultura e do desenvolvimento e suas relações entre si e traz alguns elementos chaves para a discussão como o território (a territorialidade, o lugar), a identidade e o planejamento do desenvolvimento a partir da cultura regional. O estudo expõe desafios e contradições teóricas e práticas, além de questionamentos: como estrutura os objetivos e os pressupostos da política regional. A análise parte dos elementos substantivos da abordagem territorial cultural identitária da política e como a mesma é conformada no planejamento governamental e nas políticas públicas do estado.

Conforme Lustosa da Costa (2013), um projeto de transformação calcado num paradigma cultural de desenvolvimento a partir da cultura requer revolucionar a forma de planejar e gerenciar a ação para o desenvolvimento, o que implica considerar a busca por um sistema local que não signifique exclusão ou isolamento, mas pelo contrário, que abra novas oportunidades no campo social, econômico, político e institucional e, no caso do estado da Bahia, com base territorial.

O artigo está organizado em quatro partes principais, além desta introdução e de uma breve conclusão. A segunda seção traz uma breve discussão sobre o conceito de desenvolvimento e suas diferentes perspectivas. A terceira seção aborda o elemento cultural nas abordagens sobre o desenvolvimento. E a quarta seção traz uma leitura da política de desenvolvimento regional do estado da Bahia. Na quinta seção se analisa a cultura como estratégia para a elaboração das políticas públicas do estado da Bahia.

\section{O desenvolvimento em diferentes perspectivas e ressignificações}

Desde meados do século XX, um fantasma percorre o mundo... Este fantasma é o desenvolvimento. E embora a maioria das pessoas, certamente, não acredite em fantasmas, pelo menos em algum momento acreditou no "desenvolvimento", se deixou influenciar pelo "desenvolvimento", perseguiu o "desenvolvimento", trabalhou pelo "desenvolvimento", viveu do

\footnotetext{
2 Irecê, Velho Chico, Chapada Diamantina, Sisal, Litoral Sul, Baixo Sul, Extremo Sul, Médio Sudoeste da Bahia, Vale do Jiquiriçá, Sertão do São Francisco, Bacia do Rio Grande, Bacia do Paramirim, Sertão Produtivo, Piemonte do Paraguaçu, Bacia do Jacuípe, Piemonte da Diamantina, Semiárido do Nordeste II, Litoral Norte e Agreste Baiano, Portal do Sertão, Sudoeste Baiano, Recôncavo, Médio Rio de Contas, Bacia do Rio Corrente, Itaparica, Piemonte Norte do Itapicuru, Metropolitano de Salvador, Costa do Descobrimento (BAHIA, SEPLAN, 2017).
} 
"desenvolvimento"... E é muito provável que siga fazendo isso ainda hoje (ACOSTA 2016, p.82).

O desenvolvimento enquanto conceito e discurso a ele pertinente está situado em espaço e tempo específicos ao longo da história. Diferentes teorias e intensos embates teóricos e ideológicos contribuíram para a formação e ampliação do conceito e para a criação de um conjunto de ação política para o desenvolvimento e para o aprofundamento do debate sobre o tema.

O debate sobre o desenvolvimento é extenso e conflituoso. Inúmeros conceitos foram sendo estabelecidas historicamente e, não há, hoje, uma definição exata e unânime do que seja o desenvolvimento (OLIVEIRA, 2010).

Arturo Escobar (2014) coloca três momentos importantes das conceituações sobre o "desenvolvimento".

A lo largo de los primeros cincuenta años (1951-2000), la conceptualización sobre el desarrollo en las ciencias sociales atravesó por tres momentos principales, correspondientes a tres orientaciones teóricas contrastantes: la teoría de la modernización en las décadas de los cincuenta y sesenta, con su teoría aliada de crecimiento económico; la teoría de la dependencia y perspectivas relacionadas en los años sesenta y setenta; y las aproximaciones críticas al desarrollo como discurso cultural en los años noventa (...) Estos tres momentos pueden ser clasificados, de acuerdo con los paradigmas originarios de los cuales emergieron como: teorías liberales, marxistas y postestructuralistas, respectivamente (ESCOBAR, 2014,pp. 27-28).

Nas teorias da modernização ${ }^{3}$ a história é tratada como um processo único, integrado e integral de evolução, num caminho de mão única e destino igualmente único e já dado pelo "estágio" de desenvolvimento avançado contemporâneo do capitalismo.

Pensadores latino-americanos produziram importantes revisões do conceito de desenvolvimento, o que se traduziu num esforço analítico de entende-lo e explicá-lo, afastando-se do paradigma universal de modernização capitalista e avançando na compreensão das condições históricas, das especificidades e da trajetória do continente e de seus países. Diferentes visões sobre as características e as possibilidades do desenvolvimento surgiram nos países latino-americanos, assim como o pensamento da Comissão Econômica para a América Latina e o Caribe $(C E P A L)^{4}$, que gerou revisões contestadoras do desenvolvimento

\footnotetext{
${ }^{3}$ Os teóricos da modernização buscam explicar como se dá a passagem de um estado para outro (tradicional-moderno) e como esta passagem pode se realizar. Assim entendida, a modernização se refere à mudança numa certa direção desejada, um devir da sociedade (OLIVEIRA, 2010, pg. 15). ${ }^{4}$ A CEPAL foi criada em 1948 pelo Conselho Econômico e Social das Nações Unidas (ECOSOC) e tem sua sede em Santiago, no Chile, sendo uma das cinco comissões econômicas regionais da ONU. Seu objetivo central era monitorar as políticas direcionadas à promoção do desenvolvimento econômico da região latino-americana, assessorar as ações encaminhadas para sua promoção e contribuir para
} 
convencional a partir do método do estruturalismo histórico e a teoria da dependência, o capitalismo tardio e o pós-desenvolvimentismo

$\mathrm{Na}$ longa história de sua existência, o conceito de desenvolvimento sofreu modificações em função das posições teórico-ideológicas de seus formuladores, das origens filosóficas e do contexto temporal e espacial onde foram construídas. Existem diferentes interpretações tanto no debate teórico científico, quanto no entendimento do conceito na formulação de projetos políticos.

Conforme destaca Barbosa da Silva (2012), a necessidade de se repensar modelos hegemônicos causadores de assimetrias e injustiças aliada a uma série de transformações institucionais e econômicas aponta para a emergência de um novo paradigma de desenvolvimento, onde a cultura tem ganhado centralidade.

O economista brasileiro Celso Furtado ofereceu especial contribuição ao debate conceitual do desenvolvimento, ao contestar os argumentos essencialmente econômicos e ao colocar a discussão sobre o tema desenvolvimento em termos culturais. Ele destaca que a cultura de uma sociedade é o que define a sua visão de desenvolvimento e o que condiciona a sua consecução, ou seja, uma sociedade desenvolve-se na medida da sua compreensão sobre o sentido e o significado do desenvolvimento, e esse significado é, em grande parte, construído no domínio da cultura (FURTADO, 2012, p. 78-80).

O autor demonstra em suas reflexões a preocupação em articular as políticas econômica (cuja tônica é a acumulação), social (cujo foco é a inserção) e cultural (cujo essencial é a criatividade e a consequente transformação), ou seja, estabelece os elos entre os meios e os fins do processo de desenvolvimento, apontando os vínculos existentes entre as dimensões econômica, social e cultural. Furtado defende a ação do Estado através da articulação política e institucional para criar as condições que propiciem o exercício da criatividade do homem, ou seja, as iniciativas surgidas na sociedade.

O desenvolvimento, para Furtado, seria menos o resultado da acumulação material do que um processo de invenção de valores, comportamentos, estilos de vida, "de criatividade", ou seja, um processo cultural.

Arturo Escobar (2015) e Alberto Acosta (2016) se inserem numa corrente do pensamento crítico sobre o desenvolvimento que propõe um novo fundamento epistêmico para o conceito de desenvolvimento, defendendo a necessidade de outros discursos fundamentadores de práticas que sejam plurais e que não se sobreponham às culturas locais. Aponta a possibilidade da construção não de desenvolvimentos "alternativos", ou seja, caminhos diferentes para o mesmo

reforçar as relações econômicas dos países da área, tanto entre si como com as demais nações do mundo promover o desenvolvimento social e sustentável (CEPAL, 2016 s./p). 
conceito e que permanecem na lógica hegemônica, mas sim de "alternativas ao desenvolvimento". E expõe ser necessário construir um modelo a partir das representações de práticas alternativas em cenários locais concretos particularmente no marco da ação coletiva e da mobilização política e na coexistência de modelos sociais diversos, nas resistências locais existentes dos movimentos que lutam para preservar suas tradições e modos de vida particulares

Alberto Acosta destaca que o desenvolvimento tem sido um sistema com desigualdades onde as promessas de progresso feitas há mais de quinhentos anos e as da modernização que ganharam o mundo a partir da década de 1950, não se cumpriram. E não se cumprirão, segundo o autor.

Ele propõe a filosofia e a utopia do Bem Viver; filosofia calcada na urgência de se construir sociedades mais solidárias e sustentáveis. Sugere, como Escobar, uma quebra de paradigma que supere o fatalismo do desenvolvimento, propõe uma alternativa ao desenvolvimento que revalorize as diversidades culturais e modos de vida suprimidos pela homogeneização e universalização.

O Bem Viver, refere-se à vida em pequena escala, sustentável e equilibrada, como meio necessário para garantir uma vida para todos e a própria sobrevivência da espécie humana e do planeta. O fundamento são as relações de produção autônomas, renováveis e autossuficientes. O Bem Viver se expressa na articulação política da vida, no fortalecimento de relações comunitárias e solidárias, assembleias circulares, espaços comuns de sociabilização, parques, jardins e hortas urbanas, cooperativas de produção e consumo consciente, comércio justo, trabalho colaborativo, com diversidade e respeito ao próximo (ACOSTA 2016, p.16).

Como discorre Brizuela, (2014), discursos sobre identidade e diversidade cultural, do reconhecimento dos fatores intangíveis como os povos, as tradições, as crenças, a educação, a saúde, os direitos, as liberdades, os diferentes modos de vida e produção, a invenção, a criatividade, a natureza, enfim, toda uma estrutura social e cultural vem possibilitando diversas conexões e interações entre cultura e desenvolvimento, trazendo importantes reflexões e reafirmando a centralidade que tem a cultura na circunstância contemporânea.

Conforme Paulo Miguez (2006) o lugar que ocupa hoje a cultura no processo de desenvolvimento, é certamente o lugar da transversalidade, ou seja, ao transitar fora das fronteiras de seu campo singular restrito e específico estabelecendo enlaces com outras dimensões da vida em sociedade assumindo uma função de importância no que diz respeito à estrutura e à organização da sociedade, aos processos de desenvolvimento, do meio ambiente global e à disposição de seus recursos econômicos e materiais. A cultura se impõe como fator transversal em planos e graus diferenciados, atravessando a política, a economia e os domínios da administração e da gestão, na religião, no campo jurídico e das 
tecnologias, e agências que definem as agendas desenvolvimentistas entre outros setores.

No Brasil, a partir dos anos 2000, as relações entre cultura e desenvolvimento passaram a integrar o debate político que em certo período foi capaz de oferecer recursos conceituais, epistemológicos e institucionais que permitiram repensar a nossa trajetória truncada e excludente de desenvolvimento até então. Os conceitos de cultura, território e desenvolvimento regional foram gradativamente ganhando densidade na forma de projetos e políticas públicas para o desenvolvimento.

Conforme destaca Antônio Rubim (em comunicação pessoal em 10 de outubro de 2015), nos anos de governo do Partido dos Trabalhadores, a cultura deixou de ser apenas um elemento formal e decorativo e ganhou um caráter substantivo, com o fortalecimento do Ministério da Cultura ,com o reconhecimento da diversidade do país, com a expansão da liberdade e a efetivação, mesmo com limitações, de direitos individuais, políticos, econômicos, sociais, ambientais e especialmente culturais.

Dessa forma, expõe Antônio Rubim, cabe hoje, especial e urgentemente, repensar o lugar da cultura no processo de transformação e desenvolvimento do país, sendo impossível aceitar a sua marginalização e negar sua centralidade nos modelos de desenvolvimento e transformação social, sobretudo o brasileiro.

Lustosa da Costa corrobora o debate sobre a transversalidade da cultura no processo de desenvolvimento. O autor defende a premissa de que a cultura é um fator primordial no processo de desenvolvimento e apesar de todas as dificuldades para incorporá-la a um projeto de desenvolvimento, a dimensão cultural hoje passou a ser compreendida e valorizada.

O autor reafirma a necessidade de se englobar as dimensões ambiental, econômica, social, institucional e simbólica da cultura no processo de desenvolvimento e destaca que, se consideradas em todo seu alcance, essas dimensões são integradas e co-dependentes. Ainda que operando em níveis e tempos diferentes, sempre terão impactos mútuos.

O conceito de Bacia Cultural defendido pelo autor destaca os aspectos institucionais e os elementos históricos e culturais que caracterizam o território como dimensões constituintes do processo de desenvolvimento. Com isso ganham relevância os elementos relativos à identidade, que constituem fatores de agregação social.

O conceito de Bacia Cultural toma como referência o paradigma que entende o desenvolvimento como um processo de coordenação e sinergia entre vários processos de desenvolvimento local e regional, que tente integrar todos os mecanismos de intervenção governamental ou não governamental colocando-os 
dentro da perspectiva da cultura regional definindo um conjunto de objetivos e ações que considere os elementos históricos e culturais caracterizadores do território no processo de formulação e implementação de Planos de Desenvolvimento Regional. Para Lustosa da Costa:

Se o desenvolvimento for visto como um processo de transformação social orientado para a valorização da existência humana, a relevância da dimensão cultural fica mais evidente. A pertença a um determinado universo cultural é a base da identidade. Reconhecer-se membro de uma comunidade é parte constitutiva da autoestima individual e coletiva e fonte de felicidade. Uma e outra tornam possíveis a construção de projetos comuns, a formação da confiança mútua e o estabelecimento de relações de cooperação, vale dizer, a acumulação de capital social. Por outro lado, são as diferenças culturais que ensejam as trocas simbólicas e materiais. Identidade, alteridade, capital social e cooperação são manifestações da cultura e fatores fundamentais de fortalecimento institucional e político, de progresso material e de desenvolvimento sustentável. Assim, o planejamento regional não pode descurar dos elementos culturais em qualquer esforço de prospectiva e ordenamento de ações de longo prazo (Ibid., p.192).

Território e Identidade são categorias importantes no pensamento sobre desenvolvimento regional de Lustosa da Costa. Há o entendimento de que na transformação da realidade regional, pensar as relações entre cultura e desenvolvimento deve ser o primeiro passo para a formulação de estratégias de desenvolvimento viáveis, efetivas e legítimas.

\section{Os Territórios de Identidade da Bahia - estratégia de desenvolvimento regional com abordagem cultural}

Um primeiro aspecto que devemos ter em mente é que território e identidade são conceitos interligados, o que nos ajuda a entender porque atualmente 0 objeto do desenvolvimento deixa de ser um setor, um grupo de população ou uma dimensão específica para passar a ser um território com suas complexidades, articulações e riquezas (Gestor do governo do estado da Bahia, comunicação pessoal, 07 de outubro de 2015).

Os Territórios de Identidade da Bahia, como uma política de desenvolvimento regiona,I se apresentam a partir de uma apropriação/apreensão do material, do concreto, do simbólico, do sociocultural e identitário, do espaço socialmente construído, ou seja, percebido, vivido e concebido como paradigma e base estratégica para o desenvolvimento do estado. Em 2007, o governo da Bahia implementou uma nova regionalização institucional do estado em Territórios de Identidade (TI) que priorizou uma abordagem sociocultural para o conceito de região, "territórios de identidade", em substituição a uma abordagem estritamente econômica. 
O território é a base geográfica da existência social, que engendra todos os tipos de relações, onde tudo acontece, ou seja, é no território que a população constrói a sua identidade e os seus sentimentos de pertencimento onde expressa seu patrimônio cultural e define o seu destino (SECRETARIA DE PLANEJAMENO DO ESTADO DA BAHIA [SEPLAN], 2015).

As ações implementadas pelo Governo da Bahia baseiam-se em aspectos fundamentais para o planejamento governamental do estado, que são: os campos socioeconômicos, físico-cultural, político-organizativo e simbólico cultural, que constituem o território e, reunidos num espaço geográfico, propiciam a formação de identidades individuais e coletivas que evocam sentimentos de pertencimento que contribuem para a sua identificação enquanto território único. (SEPLAN, 2015).

O estado incorporou uma pluridimensionalidade de aspectos nas ações do planejamento governamental, tendo como pressuposto norteador dessa abordagem o sentimento de pertencimento da população de cada território de identidade e a participação ativa da sociedade organizada na definição dos rumos dos seus territórios. A regionalização territorial se articula numa abordagem política que coloca a cultura no centro de um processo de regionalização institucional do território estadual (SERPA, 2015).

E sobre esse ponto Antônio Rubim ${ }^{5}$ lembra que:

[...] os territórios de Identidade além de falar em "território", falam do conceito de "identidade", ou seja, a identidade, a cultura daqueles lugares que pertencem àqueles territórios são fundamentais na sua conformação (Comunicação pessoal, 10 de outubro de 2015).

A definição e conceituação de Territórios de Identidade advêm de uma metodologia utilizada pelo Ministério de Desenvolvimento Agrário (MDA) e implementada na Política de Desenvolvimento Territorial e no Programa de Desenvolvimento Sustentável de Territórios Rurais (PRONAT). Os programas e as políticas públicas para o desenvolvimento no âmbito do governo federal a partir de 2003 passaram a valorizar a participação popular e a inclusão social, incorporando esses conceitos ao modelo de desenvolvimento territorial no país.

$\mathrm{Na}$ abordagem territorial ${ }^{6}$, o território é o ponto focal do desenvolvimento, ganhando função normativa, isto é, representa o elemento organizativo das

\footnotetext{
${ }^{5}$ Antônio Albino Canelas Rubim é professor titular da Universidade Federal da Bahia-UFBA, docente do Programa Multidisciplinar de Pós-Graduação em Cultura e Sociedade. É autor, organizador de diversos livros ligados à Cultura e à Política Cultural. Antônio Rubim ocupou o cargo de Secretário de Cultura do estado da Bahia durante o período de 2011 a 2014.

${ }^{6} \mathrm{O}$ enfoque territorial do desenvolvimento no Brasil, como na América Latina, representa uma das principais inovações no âmbito das políticas públicas nos anos 2000; no que se refere a uma abordagem intersetorial, que envolve o conjunto da dimensão da vida social, política e econômica local e também na superação no âmbito do planejamento governamental de formas verticalizadas e
} 
propostas de desenvolvimento, ou seja, é a partir do local onde se desenrolarão as políticas de desenvolvimento (SERPA, 2015).

A política territorial do governo da Bahia assume contornos diferenciados e uma lógica mais ampla no processo de divisão e reorientação da política pública de desenvolvimento que, de forma gradativa, foi assumindo a perspectiva de política de Estado, incorporando pressupostos, instrumentos específicos e inovadores na gestão e construção das políticas públicas.

Sobre o conceito de Território de Identidade, adotado como unidade de planejamento governamental do estado da Bahia, Thiago Xavier ${ }^{7}$ nos esclarece:

A ideia que buscamos no início era buscar a definição de território dentro de uma conceituação ampla, que absorvesse as diversas dimensões, econômica, social, cultural, ambiental para adotar uma delimitação regional que respeitasse essas dimensões. $\mathrm{E}$ a síntese desse conceito é o sentimento de pertencimento das pessoas. As pessoas se sentirem pertencentes àquele espaço é porque essas dimensões evidentemente estão respeitadas e contempladas (Comunicação pessoal, 12 de outubro de 2015).

O conceito principal associado ao de território de identidade é o de "pertencimento". Os indivíduos pensam em si mesmos como membros de uma coletividade na qual seus símbolos, em múltiplos aspectos, estão atrelados àquele espaço geográfico, ou seja, há um sentimento de pertencerem àquele território (SEPLAN, 2015).

\begin{abstract}
Assim, o processo de estruturação dos territórios da Bahia envolve múltiplos aspectos: culturais (costumes e valores, religiosidade, manifestações folclóricas, gastronomia, produção cultural, visão da sociedade sobre si mesma e outras formas de expressão da realidade local), geoambientais (características geográficas e ambientais, como topografia, hidrografia, clima, fauna, flora, solo, ecossistemas, preservação dos recursos naturais, defesa do princípio da sustentabilidade), político-institucionais (capacidade de formação de capital social -capacidade de negociação e cooperação da comunidade em prol de objetivos coletivos-, sua institucionalização em organizações sociais e outras formas, grau de articulação política das forças sociais no território) e econômicos (base produtiva, especialização econômica, conformação dos mercados e fluxos comerciais, produção e distribuição de renda, infraestrutura voltada à produção e às atividades econômicas, capacidade de transporte e comunicações, capacidade de articulação dos recursos locais para gerar oportunidades de trabalho e renda, etc.) (SEPLAN, 2015).
\end{abstract}

centralizadas (os modelos tipo top down) de gestão para diversificar e incorporar demandas, vozes e as forças sociais e locais dos territórios (modelos tipo bottom up). (FAVARETO \& LOTTA, 2017).

7 Thiago Xavier é economista, mestre pela Universidade Federal da Bahia, é servidor do estado da Bahia desde 2002, atualmente é diretor de planejamento territorial do estado. Thiago Xavier nos concedeu entrevista para esta pesquisa em Salvador-BA, no mês de outubro de 2015. 
Conforme Thiago Xavier, o primeiro desafio na delimitação dos territórios é promover a discussão a fim de que a população, de maneira articulada, partindo de relações de identidade, inicialmente, tornasse possível delimitar esses territórios. Em 2007 o governo da Bahia adotou essa regionalização e a denominação Territórios de Identidade como regionalização oficial, ordenamento territorial e unidade de planejamento do estado.

Território de Identidade é o agrupamento identitário municipal formado de acordo com critérios sócio-culturais, econômicos e geográficos e reconhecidos pela sua população como espaço historicamente construído ao qual pertence, com identidade que amplia as possibilidades de coesão social (Governo do Estado da Bahia, Decreto no 12.354/2010).

A Bahia absorveu bem o enfoque territorial devido a sua grande diversidade sociocultural e econômica expõe Thiago Xavier.

O estado é muito diversificado e por isso ter formulado políticas homogêneas no passado dentro dessa diversidade enorme que temos na Bahia transformou o ativo do estado, que é justamente a sua diversidade, em um passivo que é a desigualdade regional que ainda persiste em todo o estado (Comunicação pessoal, 12 de outubro de 2015).

E ressalta:

Os Territórios de Identidade forçam o estado a pensar políticas públicas específicas para cada território e esse é o desafio da gestão estatal; pensar as políticas a partir da diversidade e estimular as articulações intersetoriais e as transversalidades entre as políticas (Comunicação pessoal, 12 de outubro de 2015).

A política de desenvolvimento da Bahia, estruturada a partir do território e sua pluridimensionalidade, implica ações e políticas pensadas e implementadas mediante o autoconhecimento de grupos, agrupamentos sociais, e do envolvimento plural de atores e de suas aproximações, sendo assim a participação social no processo de implementação de políticas públicas nos territórios de fundamental importância.

A participação social no ciclo das políticas do estado da Bahia é entendida a partir da ideia de gestão social, descentralizada e participativa. A política regional busca na participação popular sua efetivação por intermédio de arranjos institucionais conformados com os territórios.

Ao assumir como elemento essencial da Estratégia de Desenvolvimento a incorporação da dimensão territorial na formulação e implementação do Plano de Governo, o Governo Estadual adotou o conceito de Território de Identidade para promover a organização territorial do Estado. Esta decisão reflete a busca 
de uma metodologia adequada para assegurar a efetividade do planejamento territorial. A gestão social dos territórios se dará através da constituição dos Fóruns de Desenvolvimento Territorial, espaços da sociedade civil onde são possíveis a articulação dos interesses dos diversos atores, a interlocução com o Poder Público e o monitoramento das políticas públicas incidentes no território (SEPLAN, 2015).

O estado formalmente sofisticou os instrumentos de gestão e de participação com a criação de instâncias participativas e espaços públicos de participação social, o que se pode dizer que vem aproximando, de certa forma, a sociedade e o Estado na articulação das políticas públicas do estado.

Segundo Thiago Xavier, o primeiro passo nessa direção de aproximação com a sociedade foi dado no Plano Plurianual (PPA) de 2008-2011, com suas ações e metas territorializadas.

\begin{abstract}
A Bahia foi o estado que mais aperfeiçoou e sofisticou os instrumentos de política territorial e de participação social. O PPA do Estado passou a ter um caráter estratégico reforçando a função planejamento; a Bahia foi o estado que mais aderiu a esse novo modelo ${ }^{8}$ que acreditamos ser um modelo que comunica melhor dentro do governo e para a sociedade. Essa estrutura facilita o processo de participação social, a sociedade é chamada a participar. Hoje, o método já está inserido no sistema coorporativo de planejamento do estado, as escutas não são uma coisa a parte, as demandas territoriais e setoriais são inseridas no FIPLAM $^{9}$ que já funciona há três anos (Comunicação pessoal, 12 de outubro de 2015).
\end{abstract}

A política traz contornos inovadores, pois a gestão social é um elemento presente em toda a esfera do projeto estruturante da política regional, o que pode possibilitar no território ações de inovação sociopolíticas, uma vez que "o envolvimento pleno e ativo" dessas forças sociais voltado à promoção do desenvolvimento pode promover um processo de aderência ao cotidiano das pessoas e das instituições territoriais e podem romper inércias e provocar mudanças na estrutura, possibilitando transformações locais e territoriais. 0 principal instrumento de gestão estratégica do estado da Bahia é o Plano Plurianual (PPA). O PPA do estado da Bahia passou a ser dividido em áreas temáticas e

${ }^{8} \mathrm{O}$ Governo da Bahia em 2007 passou a adotar uma nova metodologia de planejamento fundamentada nos temas estratégicos que teve como base os conceitos formulados pelo Ministério do Planejamento, Orçamento e Gestão a partir do ano de 2003. Organizado em temas, o planejamento incorpora a lógica intersetorial e transversal das políticas públicas, permitindo uma maior articulação entre os níveis estratégico, tático e operacional. Inaugura uma nova metodologia, em conformidade com as orientações emanadas do Governo Federal, tendo como principal motivação a busca por um caráter mais estratégico para o Plano, criando condições efetivas para a formulação, a gestão e a implementação de políticas públicas. No novo modelo, com o escopo ampliado de uma perspectiva setorial para uma escala de Governo, os programas temáticos foram concebidos a partir das diretrizes estratégicas, definidas para os diversos temas, associados aos eixos estruturantes (SEPLAN, 2015).

${ }^{9}$ O FIPLAN é o sistema integrado de planejamento, contabilidade e finanças do estado da Bahia. 
contribuiu como impulso inicial para que outros processos consultivos fossem realizados na Bahia. ${ }^{10}$

A atuação governamental e o planejamento organizado em temas incorporaram a lógica intersetorial/transversal das políticas, permitindo uma maior articulação entre os níveis estratégico, tático e operacional, como expõe Thiago Xavier (Comunicação pessoal, 12 de outubro de 2015).

Um fato que revela uma mudança na construção do Plano Plurianual do estado (PPA) são as propostas construídas a partir dos Planos Participativos ${ }^{11}$, uma vez que esses também passaram a ser temáticos e por cada território, ou seja, são 27 PPAs territoriais dentro do PPA do estado e cada PPA territorial tem seu respectivo PPA-participativo. Os investimentos dos recursos do governo do Estado da Bahia são planejados no âmbito do PPA, assim a territorialização e tematização do PPA é uma inovação importante no sentido que se torna peça organizadora do conjunto do orçamento e planejamento governamental.

Há dez anos o governo do estado da Bahia vem tratando a política territorial como política de Estado. Institui em lei ${ }^{12}$ o Conselho Estadual de Desenvolvimento Territorial (Cedeter) e os Colegiados Territoriais de Desenvolvimento Sustentável (Codeter's), o Comitê de Acompanhamento do Plano Plurianual (CAPPA), o Plano Territorial de Desenvolvimento Sustentável (PTDS), o Plano Plurianual Participativo (PPA-P) e o Zoneamento Ecológico Econômico (ZEE).

Os avanços na criação desses espaços, de métodos de participação social consulta e controle, juntamente com a construção de uma narrativa na qual a região é a escala de organização dos problemas e investimentos, é uma inovação de formas de governança e de coordenação governamental e política (FAVARETO \& LOTTA, 2017).

A política de desenvolvimento territorial do estado da Bahia adotou um novo desenho ao criar espaços institucionalizados de discussão e negociação das políticas públicas, e nessa direção é considerada uma inovação, pois com esses novos espaços houve o aumento qualitativo e quantitativo da participação das populações nas discussões das políticas de seus territórios e maior acesso à informação.

10 É o caso das Conferências Territoriais de Cultura, de Educação, de Direitos Humanos, de Comunicação, de Juventude, de Igualdade Racial, entre outras.

11 O PPA Participativo é uma iniciativa inédita do Governo do estado, em que representantes dos mais variados segmentos, como movimentos sociais, produtores, comerciantes, cooperativas, indígenas, quilombolas, pescadores, professores, estudantes, ambientalistas, agentes culturais e de turismo, acadêmicos, religiosos, agentes públicos, ONGs, fóruns, conselhos, entre outros, puderam sugerir propostas e decidir sobre os temas prioritários para os Territórios de Identidade (SEPLAN, 2015).

${ }^{12}$ A lei no 12.214 de 29 de dezembro de 2014 dispõe sobre os princípios, diretrizes e objetivos da Política de Desenvolvimento Territorial do Estado da Bahia. 


\section{A Cultura nos Territórios de Identidade}

Os Territórios de Identidade como unidade de planejamento e política de desenvolvimento regional do estado da Bahia vêm mudando a forma de pensar e conceber a cultura em suas políticas públicas ${ }^{13}$.

A amplitude do conceito de cultura utilizado não apenas delineia a extensão do objeto das políticas do estado, mas comporta questões a serem enfrentadas por tais políticas no âmbito local, regional, nacional, macrorregional e global em um estágio societário em que as conexões da cultura adquirem um lugar analítico relevante (Antônio Rubim, comunicação pessoal, 12 de outubro de 2015).

A cultura tomada como um dos pressupostos da política de desenvolvimento regional ocupa um lugar privilegiado nas políticas do estado, na medida em que passaram a integrar as diferentes agendas. Deste modo, as demais instituições e as diferentes secretarias e pastas de governo puderam absorver conceitos, compreensões e visões que estão no domínio do simbólico e do intangível em relação à identidade local dos 27 Territórios de Identidade da Bahia.

A complexidade da abordagem territorial e identitária está associada à sua multidimensionalidade e intersetorialidade, que são constituídas por outros conceitos como identidade, espaço, territorialidade e integração, favorecendo o planejamento governamental em sua pluridimensionalidade complexa (CRUZ, 2015, p.162).

Nessa perspectiva, com a prioridade estratégica de descentralizar as ações, democratizar o processo de planejamento, a execução e avaliação dos programas e projetos, a Política de Desenvolvimento Territorial surge como um instrumento inovador e desafiador para o alcance dos propósitos referidos na sua política de desenvolvimento regional.

Torna-se de suma importância a formulação de um programa que se constitui num instrumento de planejamento das ações que incorpora ao conceito de território as dimensões da cultura. É esta agregação ao programa que facilita pensar a cultura de modo estruturante e transversal no planejamento governamental. As expressões e manifestações culturais conformam 0 programa na medida em que são reconhecidas no território, espaço direcionador das políticas públicas e onde a ação do Estado acontece (SEPLAN, 2015).

\footnotetext{
13 O relatório oficial do governo "Cultura como Estratégia de Desenvolvimento", de 2008, aponta claramente em seu texto esta preocupação, além de indicar uma mudança na perspectiva de entendimento da própria cultura (SECULT, 2008).
} 
A estrutura territorializada do PPA baiano hoje tem conseguido fazer com que a cultura ganhe mais relevância, não é mais um tema periférico, como afirmou também Thiago Xavier, da SEPLAN.

A cultura, hoje, está inserida na estrutura de estado. A cultura na Bahia se relaciona com diferentes segmentos e setores, mas ainda é muito incipiente esse processo. Ainda, na cabeça das pessoas, é a "madeira cortada, a indústria que pega a madeira corrói, mistura, derrete o metal que é o progresso". Ainda é difícil para a sociedade entender que aspectos culturais estão ligados ao nosso desenvolvimento e que são alavancas para o futuro, para nossas formas de vida e de melhoria da qualidade de vida de nossa população (Comunicação pessoal, 12 de outubro de 2015).

Ângela Andrade ${ }^{14}$ destaca que o sentimento de pertencimento adotado pelo Governo do Estado na revelação dos territórios de identidade perpassa logicamente, a cultura, ou seja, laços de identidade regionais. O fortalecimento da cultura em todos os 27 territórios configura um importante instrumento para a consolidação da política de maneira geral, incentivando a participação popular no desenvolvimento, conforme relatou Ângela Andrade em entrevista concedida à pesquisa.

Para Antônio Rubim, secretário de Cultura do estado no período de 2011 a 2014, a regionalização e reorganização do estado em Territórios de Identidade é uma conceituação muito cara ao campo da cultura.

Os ordenamentos regionais no país e, sobretudo na Bahia, têm sido baseados em dimensões geográficas, como o clima, etc., outras vezes econômicas, ou seja, critérios econômicos, geográficos. Os Territórios de Identidade acenam para outra coisa, além de falar em território, falam de identidade, que a identidade daqueles lugares pertencentes àqueles territórios são fundamentais nas suas conformações. Então é obviamente que o conceito de identidade está ligado ao campo da cultura, e desse modo o conceito de Território de Identidade introduz em seu próprio conceito de regionalização que a cultura é importante, que ela faz parte da regionalização/classificação do estado (Comunicação pessoal, 10 de outubro de 2015).

Paulo Miguez ${ }^{15}$, sobre a regionalização/territorialização no estado, destaca:

\footnotetext{
${ }^{14}$ Ângela Andrade foi superintendente territorial da Secretaria de Cultura do Estado da Bahia no período de 2007 a 2010.

${ }_{15}$ Paulo Miguez é cidadão baiano. Foi Assessor Especial do Ministro Gilberto Gil e Secretário de Políticas Culturais do Ministério da Cultura, de 2003 a 2005, e membro do Conselho Estadual de Cultura da Bahia, entre 2009 e 2011. É pesquisador da área de estudos socioeconômicos da cultura; políticas culturais; e estudos da festa, com ênfase no carnaval. Atualmente é Vice-Reitor da Universidade Federal da Bahia para o quadriênio 2014-2018. Graduado em Ciências Econômicas pela Universidade Federal da Bahia. UFBA (1979), mestre em Administração (UFBA, 1995) e doutor em Comunicação e Culturas Contemporâneas (UFBA, 2002). É Professor Associado do Instituto de Humanidades, Artes e Ciências da UFBA e professor permanente do Programa Multidisciplinar de Pós-Graduação em Cultura e Sociedade (UFBA), do qual foi coordenador entre 2010 e 2012, e pesquisador do CULT-Centro de Estudos Multidisciplinares em Cultura (UFBA).
} 
O estado e seus territórios são muito diferentes entre si. Essa grande diversidade é o nosso desafio. Então não tenho a menor dúvida que essa regionalização territorial contribuiu para o alargamento na forma de pensar e implementar as políticas nos territórios e, de certa forma, tentar abarcar essa especificidade que é a grande diversidade identitária da Bahia (Comunicação pessoal, 08 de outubro de 2015).

O território como lugar de pertencimento pressupõe, para muitos grupos e segmentos da sociedade civil, que o território é um instrumento político reivindicatório que subsidia lutas políticas, sobretudo de grupos subalternos, tornando-se assim algo necessário à prática social.

Lula Dantas ${ }^{16}$, representante do território de identidade do Litoral Sul, sobre sua participação nas políticas do estado, expõe:

Sou babalaxé no terreiro de AséOyaFunké, comunidade de nação Ketu dedicado à orixá Oya. A associação hoje é ponto de cultura, mas já funciona há quarenta anos, no mesmo local na minha comunidade, em Itabuna, e que através da divulgação e promoção da cultura da sua comunidade e que a visibilidade aumentou e como representantes dos movimentos socioculturais entramos em campos de batalha e obtivemos assento e voz antes inimagináveis para os povos de culturas tradicionais. É evidente que não foi de dez anos pra cá que estamos lutando por direitos, reconhecimento e acesso, estamos na luta há muitos anos. Há quinhentos anos que meu povo luta por direito ao território, à cidadania e à identidade. Enquanto comunidade tradicional e cultural negra, chegamos a um reconhecimento institucional através do Ponto de Cultura que vem nos dando certa visibilidade e possibilidade de articulação política com outros movimentos e liderança, que tem enriquecido muito nosso processo de formação enquanto militantes e possibilidades de interação. O que foi criado e instituído é ainda muito pouco; os espaços onde temos visibilidade, a luta e a defesa por direitos são ainda muito limitados para a efetividade de nossa cidadania e diversidade. Digo que existe ainda uma distância muito grande do Estado que queremos para o Estado que temos.

A respeito da cultura, o mesmo gestor lembra que essa integração:

Nos leva a uma participação social ainda muito nova em espaços de representação política. Penso que cultura, a pasta da cultura, as políticas culturais devem fazer o papel de interlocução e dizer para o resto do estado, para as outras pastas e para a sociedade o que representa e o que é a nossa diversidade, que sem acesso aos meios de comunicação, sem autonomia, esses grupos sempre estarão à margem, mesmo que o discurso seja de culto ao protagonismo e empoderamento da sociedade civil.

\footnotetext{
${ }^{16}$ Lula Dantas também é integrante e fundador da Associação do Culto Afro Itabunense, que promove oficinas gratuitas de tradição oral, artesanatos, capoeira, cultura digital, teatro e dança no estado, expõe que a associação existe desde 1987 e em 2008 se transformou em Ponto de Cultura, conveniado inicialmente à Secretaria Estadual de Cultura (SECULT), hoje ao Ministério da Cultura (MinC). Dantas expõe que desde 2007 participa dos fóruns sociais em seu território e desde então os trabalhos desenvolvidos e a atuação da associação tiveram mais visibilidade. Hoje a associação, como representante da cultura negra, tem assento em conselhos, fóruns e colegiados municipais, estaduais e nacionais ligados à cultura como o Conselho Setorial de Cultura Afro Brasileira e outros setores, como a educação e a saúde, por exemplo.
} 
E sobre a participação ressalta:

A participação social e política dos diferentes grupos culturais em espaços públicos, conselhos e fóruns ainda é pouca e é necessário que diálogos entre os movimentos sociais e entre as lideranças se intensifiquem. Existe ainda a necessidade que tenhamos assento e representatividade nas diversas pastas políticas. Nós, representantes da cultura negra e das religiões de matriz africana, somos diariamente marginalizados e violentados em nosso fazer cultural, que não está separado de nosso fazer político, cidadão e econômico. Nossa representatividade é, portanto, representativa de nossa militância e resistência (Comunicação pessoal, 07 de outubro de 2015).

A cultura como central no processo de desenvolvimento regional do estado ainda é um caminho longo. Nesse sentido Paulo Miguez destaca:

Temos experiências práticas que articulam cultura e desenvolvimento, quer no âmbito das políticas públicas estaduais, quer nacionais. Mas a cultura ainda ocupa lugar subalterno no campo político, seja do ponto de vista de recursos e orçamento, seja quanto à concepção de política de estado. A cultura ainda é pouco tomada como referência para o desenvolvimento aqui na Bahia e no país como um todo. A dimensão estratégica que a cultura joga no campo político é utilizada em segundo plano. O campo da cultura tem uma percepção clara da importância da cultura. Aqui no estado, por exemplo, ela ainda é vista como a cereja do bolo, traz certo encantamento, mas não entra nas discussões sérias, não é chamada, uma vez que acredito que ela deva ser o ator central desse processo. E o resultado, claro, é muito menor do que uma proposta, uma política e um trabalho dessa natureza poderiam sugerir (Comunicação pessoal, 08 de outubro de 2015).

Antônio Rubim destaca que no campo da cultura não se avançou em lugar nenhum no Brasil. Fala-se muito da centralidade da cultura, mas ela ainda não é colocada nesse lugar, ainda não se avançou. Rubim chama a atenção para a necessidade de se ter em mente que o desenvolvimento ainda não é entendido no Brasil como tendo um componente cultural e que esse componente vai desde o plano individual, porque o desenvolvimento afeta e muda os indivíduos, até o plano coletivo, na medida em que introduz mudanças sociais.

A pessoa para ser um cidadão pleno, ele tem que ter autoestima e isso tem a ver com seu lugar no mundo, um grupo tem que ter o direito de ter certa identidade social, então nesse sentido o desenvolvimento tem um componente cultural muito forte e também econômico, porque a cultura cada vez mais participa da economia da sociedade. A cultura em seu sentido amplo tem participação no desenvolvimento, mas isso ainda é muito pouco percebido infelizmente. O desenvolvimento cultural e político ainda está um pouco distante, eu digo longe de serem incorporados ao desenvolvimento. Então dito isso, é necessária uma concepção mais ampla, plena do desenvolvimento que tem uma dimensão política, cultural, social, ambiental. Ainda não é possível fazer entender como a cultura interfere nos modos de produção, de vida, na 
economia local, na questão ambiental e na sustentabilidade (Comunicação pessoal, 12 de outubro de 2015).

Assim como afirma Thiago Xavier, a política territorial cultural identitária do estado da Bahia não é uma política de compreensão imediata, a sua leitura se dá pela vivência, que faz com que tenhamos um conhecimento de como essa política se desenvolve. Promover um processo de desenvolvimento sustentável significa articular projetos e ações estruturantes em todo o estado, assim como uma rede de sustentação e apoio entre as diferentes pastas políticas e os diferentes setores da sociedade. Desta forma, através de uma adequada articulação política é possível promover de certo modo uma melhoria da qualidade de vida da população e diminuir as desigualdades regionais. É necessário um projeto político, uma estrutura administrativa, operacional e econômica mínima para que possa gerar mudanças e transformações.

\section{Conclusões}

Os Territórios de Identidade da Bahia enquanto uma estratégia política de desenvolvimento regional, territorial, cultural e identitário no debate contemporâneo sobre o desenvolvimento, ensejam muitos desafios e questionamentos para a compreensão das relações entres os conceitos e os significados de desenvolvimento, cultura, território e políticas públicas.

A política regional apresenta qualitativamente um avanço na formulação de políticas públicas para o desenvolvimento ao se localizar como uma proposta de transformação societária a partir da cultura.

A participação social é o elemento central das políticas territoriais do estado da Bahia. É notável a inovação no desenho de novas institucionalidades territoriais a partir das identidades econômicas, sociais, ambientais e culturais. O estado, de certa forma, ressignifica o arranjo institucional local, ou seja, na perspectiva dos territórios.

Apesar da distância e as contradições existentes entre o seu enunciado, seus pressupostos estruturantes, o real e o concreto das políticas públicas nos 27 Territórios de Identidade do estado, os Territórios de Identidade da Bahia trazem ricos elementos para a reflexão e o debate, sobretudo a partir dos campos epistemológicos que incorporam o elemento cultural nas conceituações do desenvolvimento.

Esta pesquisa procurou demonstrar que a dimensão cultural hoje é preponderante no debate sobre o desenvolvimento, e que ainda está longe de ser reconhecida e incorporada como centralidade nesse processo. Existem muitas maneiras de se abordar como a cultura contribui na formulação e implementação 
de políticas para o desenvolvimento. O estado da Bahia e sua política regional têm muito a dizer e a colaborar com a discussão sobre o desenvolvimento regional.

\section{Referências}

ACOSTA, A. (2016) O Bem Viver. Uma oportunidade para imaginar outros mundos. Brasil, Editora Autonomia Literária.

BRASIL BANCO NACIONAL DE DESENVOLVIMENTO ECONÔMICO E SOCIAL (BNDES) (2006) Cultura, Diversidade e Desenvolvimento. Brasília.

BARBOSA DA SILVA, Frederico; ARAÚJO, Herton Ellery (2010). Indicador de desenvolvimento da economia da cultura. Brasília: INSTITUTO DE PESQUISA ECONOMICA APLICADA (IPEA).

BARBOSA DA SILVA, Frederico (2012). "Desenvolvimento e Cultura - linhas gerais para um mapeamento conceitual e empírico", In: Mural Pesquisa, FGVExecutivo, vol.7, no 2, mar/abril.

MIGUEZ, Paulo. (2006) Cultura, diversidade cultural e desenvolvimento. Brasília, Banco Nacional de Desenvolvimento Econômico e Social.

BRIZUELA, J. (2011). Políticas Culturais para o Desenvolvimento Regional: O Caso do Programa Identidade Entrerriana (Argentina). Dissertação de Mestrado, Instituto de Humanidades, Artes e Ciências Professor Milton Santos, Universidade Federal da Bahia.

COMISSÃO DE ESTUDOS PARA A AMERICA LATINA E CARIBE. O que é a CEPAL? Recuperado em janeiro de 2015 em http://www.cepal.org/.

CRUZ, Danilo Uzêda (2015) Estado, desenvolvimento e política pública: espaços participativos na gestão dos Territórios de Identidade na Bahia. Salvador, Editora EGBA.

COLÔMBIA. Ministério da Cultura, Instituto Colombiano de Antropología. (2015). Antropología y desarrollo. Recuperado em:

http://www.ceapedi.com.ar/imagenes/biblioteca/libros/304.pdf.

GOVERNO DA BAHIA, Superintendência de Estudos Econômicos e Sociais (2012) Panorama Cultural Da Bahia Contemporânea, Caderno 92. 
GOVERNO DA BAHIA, Secretaria de Planejamento (2015) Relatório de Atividades, Salvador.

FAVARETO, A \& LOTTA, G. (2017) Inovações institucionais nas políticas para o desenvolvimento territorial em três estados brasileiros. In REDES (SANTA CRUZ DO SUL. ONLINE), v. 22, p. 11-38. Recuperado em:

https://online.unisc.br/seer/index.php/redes/article/view/10409/pdf.

FURTADO, R. (2012) Ensaios sobre cultura e o Ministério da Cultura. Rio de Janeiro, Editora Contraponto.

LUSTOSA DA COSTA, F. (2013) "Cultura, território e desenvolvimento: a bacia cultural como conceito e estratégia", In: Frederico Lustosa da Costa. (Org.) Política e gestão cultural: perspectivas Brasil e França. Salvador: EDUFBA, v.1, p. 159-194.

https://repositorio.ufba.br/ri/bitstream/ri/13178/1/Cult13_2013_Repositorio.pdf.

OLIVEIRA, J. (2010) Ordem, Instituições e Governança: uma análise sobre o discurso do desenvolvimento no sistema ONU e a construção da ordem internacional. Dissertação de Mestrado, Pontifícia Universidade Católica do Rio de Janeiro. Recuperado de:

http://www2.dbd.pucrio.br/pergamum/biblioteca/php/mostrateses.php?open=1\& arqtese $=081265010$ Indice. htm.

SECRETARIA DE PLANEJAMENTO DO ESTADO DA BAHIA (2015) Recuperada em setembro/outubro de 2015 em: http://www.seplan.ba.gov.br/.

SECRETARIA DE CULTURA DO ESTADO DA BAHIA (2015) Recuperada em setembro/outubro de 2015 em: http://www.cultura.ba.gov.br/.

SERPA, A. (2015) Territórios da Bahia. Regionalização, cultura e identidade, Salvador: Editora EDUFBA. 